\title{
Surgical outcomes in complex adult congenital heart disease: a brief review
}

\author{
Alice Chan', Amna Aijaz ${ }^{2}$, Ali N. Zaidi ${ }^{1,3}$ \\ ${ }^{1}$ Mount Sinai Adult Congenital Heart Disease Center, Mount Sinai Heart, Icahn School of Medicine at Mount Sinai, New York, NY, USA; \\ ${ }^{2}$ Department of Internal Medicine, Mount Sinai Beth Israel, New York, NY, USA; ${ }^{3}$ Children's Heart Center Kravis Children's Hospital, New York, \\ NY, USA \\ Contributions: (I) Conception and design: AN Zaidi; (II) Administrative support: AN Zaidi; (III) Provision of study materials or patients: None; (IV) \\ Collection and assembly of data: None; (V) Data analysis and interpretation: None; (VI) Manuscript writing: All authors; (VII) Final approval of \\ manuscript: All authors. \\ Correspondence to: Ali N. Zaidi MD. Associate Professor, Internal Medicine and Pediatrics, Icahn School of Medicine at Mount Sinai, 1 Gustave L. \\ Levy Place, 1190 5th Avenue, Box 1030, New York, NY 10029, USA. Email: ali.zaidi@mountsinai.org.
}

\begin{abstract}
Life expectancy of patients with congenital heart disease (CHD) continues to increase dramatically over the last few decades, primarily due to significant medical and surgical advancements in the field. Adult congenital heart disease (ACHD) patients are now living longer but continue to face morbidity and reduced long-term survival when compared to the general population. We briefly describe the growth of ACHD with a focus on surgical procedures and outcomes in the more complex congenital heart defects including Tetralogy of Fallot, Ebsteins Anomaly of the tricuspid valve, Coarctation of the Aorta, Transposition of the Great Arteries and single ventricle lesions. The advancing role of mechanical circulatory support and cardiac transplantation in ACHD patients is also highlighted. Cardiac surgery in these patients continues to improve with low surgical mortality rate and outstanding long-term outcomes and efficacy.
\end{abstract}

Keywords: Adult Congenital Heart Disease (ACHD); surgical outcomes; Coarctation of Aorta; Ebstein anomaly; Tetralogy of Fallot (ToF); Transposition of the Great Arteries; Fontan palliation; cardiac transplantation

Submitted Sep 26, 2019. Accepted for publication Dec 20, 2019.

doi: $10.21037 /$ jtd.2019.12.136

View this article at: http://dx.doi.org/10.21037/jtd.2019.12.136

\section{Introduction}

The overall population of adults with congenital heart disease (CHD) has been rising due to improvements in the diagnosis and treatment of CHD; there have been significant advancements in both the medical and the surgical care of these patients over the last six decades. Cardiac surgeons, general cardiologists and CHD sub specialists are encountering challenges as these adult patients develop new comorbidities. Patients often require long-term follow up with lifelong cardiac problems and sometimes need re-operation on surgical repairs that were done many decades ago. This brief review examines the prevalence of adult congenital heart disease (ACHD), the description of surgical procedures and outcomes of some of the more common complex CHD lesions and the surgical procedures associated with them, as well as the increasing role of mechanical circulatory support (MCS) and the need for cardiac transplantation.

\section{Prevalence of Adult CHD}

CHD consists of malformations during the development of the heart and great vessels in utero. Although the anomalies and defects in the cardiovascular system may be diagnosed later in life, they are present at birth. In the United States, approximately $1 \%$ (8.14 of 1,000$)$ of births per year have CHD (1). Many of these patients did not survive to adulthood in the past, but over the last few decades, there have been an increase in the survival rate due to medical 
and surgical advancements. Innovations in the field of CHD surgery and the move towards surgical correction and definitive repair instead of palliative procedures led to an increase in the number of survivors (2). Gilboa et al. showed a decrease in the mortality and an increase in lifespan; rather than deaths in infancy, the age at death has been steadily increasing (3). While we know the prevalence of CHD in newborns, the prevalence of ACHD has been more difficult to define (4). Studies are now not only looking at the prevalence at birth but also the percentage that survive into their teenage years and become adults (2). The estimated number of ACHD worldwide in 2010 was 1.4 million (3). This population with ACHD continues to grow as we improve the survival rate leading to a group of patients with unique health needs $(1,5,6)$.

\section{Coarctation of Aorta (CoA)}

CoA is seen in approximately 4 per 10,000 live births and represents 4 to 6 percent of all CHD $(7,8)$. CoA sometimes only affect the narrowing of the aorta, but can commonly be associated with other lesions including simple intracardiac shunt defects like a ventricular septal defect (VSD) or a bicuspid aortic valve. CoA can also be associated with more complex CHD such as hypoplastic left heart syndrome, transposition of the great arteries and atrioventricular canal defects. The diagnosis of CoA is often missed until infants develop congestive heart failure (CHF) or when older children and adults develop hypertension. Complications in patients who were unoperated or operated on during their teenage years or as an adult include accelerated coronary artery disease, stroke, aortic dissection, heart failure, and systemic hypertension.

Most commonly CoA is a discrete fibrotic posterior ridge which narrows the aorta at the insertion of the ductus arteriosus, with some infolding of the medial and superimposed neointimal tissue $(9,10)$. This localized constriction forms a shelf like stricture, with either an eccentric, central or membranous like opening. It is more common for the coarctations to be discrete or sometimes it may affect a longer segment of the aorta. A coarctation segment that is proximal to the ductus arteriosus is known as the preductal (infantile) type and CoA that is distal to the ductus arteriosus is known as the postductal (adult) type.

$\mathrm{CoA}$ is a lesion that requires lifelong cardiology follow up; patients need to be monitored for their associated anomalies, recurrent obstruction of the aorta, and ensure that the hypertension is under control. Autopsy studies in the past have shown that patients with CoA without surgical repair have a mean age of 35 years old with a mortality rate of $90 \%$ by the age of 50 (11). Comorbidities and complications that could result in death include CHF, hypertension, endocarditis, intracranial hemorrhage, and aortic rupture or dissection.

The American College of Cardiology (ACC), the American Heart Association (AHA), the European Society of Cardiology (ESC) and the Canadian Cardiovascular Society all recommend correction of CoA at an early age. The morbidity and mortality of patients with CoA are reduced when interventions are performed during their childhood years (12-15). However, if the child or adolescent is asymptomatic and preoperative evaluation rules out severe CoA and concerning associated anomalies, then repair is undertaken on an elective basis. The exact timing of intervention on these patients have been debated. If they are having CHF or significant hypertension, then it is an indication for either catheter based or surgical intervention. Since the 1940's, as initially performed by Crafoord and Nylin, the preferred treatment for CoA remains directed surgical therapy. The decision to perform percutaneous stent placement versus surgical correction is made on a case-by-case basis for those patients with sub-optimal anatomy (e.g., vessel tortuosity and/or transverse arch hypoplasia) often in collaboration with a multidisciplinary team. When there is a discrete CoA, balloon angioplasty or a transcatheter intervention with stent placement rather than surgical repair is recommended if the patient is large enough for the placement of an adult-size stent (weighing $\geq 25 \mathrm{~kg}$ ) (13).

Surgery has a long track record of effectiveness, low operative mortality and low risk of spinal injury in the modern era. The surgical approach for CoA depends on the patient's size, age at presentation, arch anatomy, and their associated lesions. Several different surgical techniques have been described in the literature which include resection with end-to-end anastomosis, patch or left subclavian flap aortoplasty, and tubular bypass grafts. Depending on the individual's anatomy, these procedures may need to be merged or modified (16). If there is complex arch repair, a median sternotomy might be necessary rather than the classic left lateral thoracotomy surgical approach. Over the years, these surgical techniques have also been improving. Historically, in infants and children in the presence of a hemodynamically significant VSD, a pulmonary artery band is often placed to limit pulmonary blood flow during a left thoracotomy for coarctation repair. In the present day, 
patients (even neonates) can have a more definitive singlestaged repair by proceeding with a sternotomy to correct both the coarctation and the VSD (16-18).

CoA surgical repairs in children and adolescents generally have decent results with a low mortality rate, but complications continue to remain a problem. Long term complications that can develop include aneurysms particularly in those patients who have had a prosthetic patch for CoA repair, subclavian flap repair, or have had prior angioplasty. Rare cases of paraplegia and paradoxical hypertension after surgical repair have been reported. Patients can also develop significant re-coarctation at the site of prior repair (16-18). These complications are usually mild and inconsequential following balloon angioplasty $(19,20)$. Risk factors for mortality include preoperative hypertension and older age at initial repair. Though still being elucidated, late mortality in patients with CoA has been associated with underlying coronary artery disease, sudden cardiac death, heart failure, cerebrovascular accidents, and ruptured aortic aneurysms. The operative and procedure-related mortality are rare $(<1$ percent of cases) with ten-year survival following CoA repair being more than $>90$ percent, but with these complications, the long-term survival is decreased compared with the general population $(21,22)$.

\section{Ebstein Anomaly}

Ebstein's anomaly is a rare congenital heart disorder ( 1 per 200,000 live births), accounting for about $0.3 \%$ to $0.7 \%$ of all cases of CHD. The true prevalence is unknown because patients with mild forms of this defect are frequently not diagnosed till later in life since their lack of symptoms may prevent the underlying pathology from being discovered until adulthood $(23,24)$. The primary abnormality in Ebsteins anomaly occurs during embryonic development of the cardiovascular system, when there is a failure of delamination of the posterior and septal leaflets of the tricuspid valve from the myocardium of the right ventricle resulting in the displacement of the attachment of the septal leaflet of the tricuspid valve into the body of the right ventricle. This causes a large portion of the right ventricle to become "atrialized". This "atrialized" segment of the right ventricle does not contribute to right ventricular function and cardiac output. In severe cases, the non-atrialized part of the right ventricle remains small and may consist of only the right ventricular outflow tract. In addition to the apical displacement of the tricuspid valve, the tricuspid valve leaflets are often abnormal. The morphology of the tricuspid valve in Ebstein's anomaly is variable and may affect the severity of the clinical presentation. Typically, the anterior leaflet is the largest leaflet and is usually attached to the tricuspid valve annulus. Due to the displaced and malformed tricuspid leaflets, and atrialization of the right ventricle result in varying degrees of tricuspid regurgitation and other associated hemodynamic consequences. The extent of leaflet displacement will determine the severity of the tricuspid regurgitation with mild regurgitation for minimally displaced tricuspid leaflets regurgitation and severe regurgitation in extremely displaced tricuspid leaflets.

The treatment varies depending on the severity of the disease and its associated congenital, structural, and electrical abnormalities (25). Associated lesions include atrial septal defects, other valvular lesions, and accessory conduction pathways such as Wolff-ParkinsonWhite (WPW) syndrome. The mean age patients are diagnosed with Ebsteins anomaly is in the middle teenage years. When diagnosed in infancy, they usually have severe disease and a less favorable prognosis, however approximately $5 \%$ of patients with Ebsteins anomaly of the tricuspid valve may survive several decades into adulthood $(24,26)$.

Treatment involves surgical procedures that offer correction of the tricuspid valve, atrialized right ventricle, intracardiac defects, surgical techniques to eliminate arrhythmias as well as palliative procedures in the neonates as a bridge to more definitive surgical treatment later in life. In patients aged 50 years or older with Ebstein anomaly, surgery is associated with good long-term survival and improved functional status, although long-term survival might be improved by performing surgery earlier (27).

Over the last few decades, various different surgical techniques are offered to treat structural abnormalities of the tricuspid valve. When possible, tricuspid valve repair is preferred over valve replacement. Bioprosthetic valves are preferred over mechanical prosthetic valves if surgical replacement is chosen. When needed, the markedly dilated, thin-walled right atrium can be resected and associated septal defects can be closed. It is important to understand the surgical plication techniques of the ventricular wall since the size of the $\mathrm{RV}$ is reduced by folding the wall of the atrialized ventricle $(28,29)$. Carpentier described the disconnection of parts of the anterior and the posterior leaflet from the functional annulus at the hinge point, thereby gaining access to the multiple attachments behind the leaflets that prevent leaflet mobility (30). The cone repair performed 
by Da Silva is a technique for the surgical reconstruction of the tricuspid valve and the RV in Ebstein anomaly. The leaflets are longitudinally attached to each other with a running suture such that the valve, which initially consisted of three separate leaflets is transformed into a valve with a single circular, cone-shaped leaflet, covering 360 degrees of the true tricuspid annulus and is called a "cone-valve" (31). A tricuspid valve replacement can be done when warranted. The prosthesis is placed at the height of the true tricuspid annulus, often with a horizontal plication of the valve annulus. To avoid damage to the atrioventricular (AV) node, the septal suture line is placed in front of the coronary sinus, thus draining the coronary sinus directly into the RV $(28,29,32)$.

The majority of patients who originally presented with arrhythmias were symptom free after tricuspid valve repair even without concurrent antiarrhythmic surgery. However, patients should be carefully evaluated and antiarrhythmic surgical procedures should be considered if open heart surgery is already being performed for Ebstein anomaly. The antiarrhythmic surgical procedures involve the accessory pathways or AV-nodal reentry tachycardia, and procedures for atrial fibrillation or atrial flutter including the Maze procedure $(27,32,33)$. Palliative surgical procedures have also been utilized which include creation of an atrial septal defect, closure of tricuspid valve with plication of the right atrium, and maintenance of pulmonary blood flow by creating a surgical aortopulmonary shunt. These procedures usually are reserved for severely ill infants with grave prognosis and are rarely performed in adults.

\section{Tetralogy of Fallot (ToF)}

ToF is a congenital cardiac defect that comprises of right ventricular outflow tract obstruction (RVOTO) VSD, aorta dextroposition (overriding aorta), and RV hypertrophy. ToF is not only one of the most common congenital heart defects representing approximately $7-10 \%$ of all $\mathrm{CHD}$, but also one of the most common cyanotic CHD with $0.23-0.63$ cases per 1,000 births (34). In adults, ToF has a prevalence of $\sim 1$ in 3,500 to 1 in 4,300 with a $75 \%$ survival at 30 years (34). Patients without treatment have a mortality rate of $50 \%$ by age six, but with advancements in cardiac surgery, children with simple forms of ToF enjoy excellent long-term survival and quality of life $(35,36)$.

Most adult patients with repaired ToF present with symptoms usually after the second or third decade of life (35). A small proportion of patients mild unrepaired tetralogy or patients with a palliative procedure (e.g., shunt placement) may present as adults without any prior reparative surgery (37). Overall, children with repaired ToF survive into adulthood, but an emphasis in long term follow up in cardiology clinics is essential. Males and females appear to be affected equally with symptoms as they age (35). After the first two decades of life, patients often have symptoms secondary to pulmonary valvular regurgitation (38). By the fourth or fifth decade of life, most survivors may become significantly symptomatic (39).

Shunt placement to relieve cyanosis was the first surgery used to repair ToF. Primary repair is currently recommended within the first 12 months of life with excellent results. Though ToF was first described earlier, no treatment was available until the 1940s. In 1944, Alfred Blalock operated on an infant with ToF and created the first Blalock-Taussig shunt between the subclavian artery and the pulmonary artery (40). The Blalock-Taussig shunt heralded a new era in neonatal cardiac surgery leading to the development of the Potts shunt (from the descending aorta to the left pulmonary artery), the Glenn shunt (from the superior vena cava to the right pulmonary artery), and the Waterston shunt (from the ascending aorta to the right pulmonary artery). In 1954, Walton Lillehei performed the first successful open surgical repair for ToF using controlled cross-circulation, with another patient serving as oxygenator and blood reservoir $(41,42)$.

Surgery to repair ToF in adults is done under cardiopulmonary bypass using cardioplegia. Once the heart is arrested, the VSD is patched closed, the infundibulum is surgically widened, and the pulmonary valve is repaired. Unlike in infants, transannular patching is infrequently performed in adult patients. Most surgeons replace or repair the pulmonary valve in adults rather than placing a transannular patch (43).

Pulmonary valve replacements are the preferred treatment for patients with pulmonary valve insufficiency since it has shown to decrease the RV back to a normal size and improve its function in the long term. This improvement in insufficiency and change in size and function, however, does not change the incidence of arrhythmias. (44). Nevertheless, surgery is eventually needed for adult patients with pulmonary valve insufficiency, but the timing of when it should occur remains debatable (45). The surgeons can implant one of two types of bioprosthetic valves, which are human tissue (homografts) or animal tissue (bovine pericardium or porcine heart valve). Both types of valves can be implanted either as part of a conduit 
in the RVOT or as denovo valves (45).

Tissue valves do not require anticoagulation, but they are also not lifelong; nearly $40-50 \%$ of the bioprosthetic valves will need to be replaced within the first decade after implantation. Since most of the adult patients with ToF are only in their second and third decade of life, it is likely these young patients may need to undergo more than one surgical procedure as they reach their thirties and forties. There have been a few surgical series on adult patients with varying postsurgical results. Data shows a survival rate in excess of $90 \%$, ten years after pulmonary valve replacement. Though the short term results of valve replacements are excellent, the long-term outcomes are considered fair (46). In the new era, innovations in endovascular technology have introduced various percutaneous interventions, with data suggesting that these techniques are both feasible and safe. Transcatheter pulmonary valves such as the Melody valve can be implanted via the femoral vein with fluoroscopy guidance (47). Although several factors have been identified to affect the survival of these patients, some of them such as planning of the surgical strategy are modifiable. The overall long-term transplant-free survival in repaired ToF is excellent $(38,48)$.

\section{Transposition of the Great Arteries}

Transposition of the great arteries (TGA) is one of the most common cyanotic congenital heart diseases in the newborn period. Despite its overall low prevalence, TGA is found in $5-7 \%$ of all patients with CHD. The annual incidence is approximately $20-30$ per 100,000 live births and it has a multifactorial inheritance. The hallmark is ventriculoarterial discordance, in which the aorta arises from the morphologic $\mathrm{RV}$ and the pulmonary artery arises from the morphologic left ventricle. Although described over two centuries ago, no dedicated surgical treatments were available until the middle of the 20th century. Surgical atrial septectomy was performed in the 1950's and the first percutaneous balloon atrial septostomy was done in the 1960s. These were palliative procedures however therapeutic surgical procedures (atrial switch operation including the Mustard or Senning procedures) and anatomic repair (arterial switch operation) have evolved over the last few decades $(49,50)$. With continuous improvement in these surgical procedures, the survival rate for infants born with TGA is now greater than $90 \%$. The anatomic classification of TGA depends on the relationship of the great arteries to each other and/ or the infundibular morphology. In approximately $60 \%$ of infants born with TGA, the aorta is anterior and to the right of the pulmonary artery [dextro-transposition of the great arteries (d-TGA)]. However, in a subset of infants, the aorta may be anterior and to the left of the pulmonary artery [levo-transposition of the great arteries (1-TGA)]. Most patients with TGA (regardless of the orientation of the great arteries) have a subaortic infundibulum, an absence of subpulmonary infundibulum, and fibrous continuity between the mitral valve and the pulmonary valve.

The primary anatomic subtypes are as follows:

(I) TGA with intact ventricular septum.

(II) TGA with VSD.

(III) TGA with VSD and left ventricular outflow tract obstruction.

(IV) TGA with VSD and pulmonary vascular obstructive disease.

\section{TGA with Intact Ventricular Septum}

The arterial switch operation (ASO) is the ideal operation for infants born with TGA. It represents a complete anatomic repair and establishes ventriculoarterial concordance. The procedure should be performed in the first few weeks of life, as the left ventricle may not be able to handle systemic pressure postoperatively if left too long in the low-pressure, low-resistance pulmonary circuit. Rarely, depending on the particular coronary artery anatomy (e.g., intramural coronary artery), coronary artery translocation may not be feasible, and an ASO is not surgically recommended. In this subgroup, an atrial level switch (Senning or Mustard procedure) carries a lower risk of surgical and short-term morbidity and mortality (51).

\section{TGA with Ventricular Septal Defect}

The preferred operation is an ASO with VSD closure. If the VSD is large and nonrestrictive and the coronary artery anatomy precludes an ASO from being performed, then a Rastelli-type intracardiac repair is warranted. A Rastelli intra-cardiac repair is often done when the infants are older to allow an adequate sized right ventricle-pulmonary artery conduit to be surgically placed (52). If the infant has significant congestive heart failure (with growth failure) due to pulmonary overcirculation, it may be advisable to either proceed with direct reparative surgery or placing a PA band during the newborn period to restrict pulmonary blood flow as an initial palliative surgical approach. 


\section{TGA with VSD and Left Ventricular Outflow Tract Obstruction}

An ASO may not be feasible due to pulmonary valve (left ventricular outflow tract) stenosis or atresia. If the VSD is unrestrictive and remote from the aorta, a Rastelli intracardiac repair could be considered (52). Rarely while waiting for a Rasteli operation, an aortopulmonary shunt placement may be needed in the neonatal period as palliation to allow for adequate pulmonary artery blood flow.

\section{TGA with VSD and Pulmonary Vascular Obstructive Disease}

These patients might not be appropriate surgical candidates because of the progressive increase in pulmonary vascular resistance (53). Some patients may experience profound right ventricular failure, but they may do well with left ventricular retraining and late ASO $(54,55)$. Most of these patients maintain normal systolic function and exercise capacity. With the ASO, long term sequelae may include chronotropic incompetence and stenosis at the supravalvular neoaortic, neopulmonary, branch pulmonary arteries, and coronary artery ostia $(54,55)$. Their overall perioperative survival rate is greater than $90 \%$ with longterm and arrhythmia-free survival at approximately $97 \%$ at 25 years. In these patients, late mortality is predominantly due to sudden cardiac death and myocardial infarction (56). Patients who undergo the atrial level switch procedure have a low mortality rate overall, but the long-term morbidities such as atrial bradyarrhythmia and tachyarrhythmia, systemic atrioventricular (tricuspid) valve regurgitation, and systemic (right) ventricular dilatation and failure are significant.

The procedure of choice for d-TGA became the ASO almost 30 years ago even though the trial period initially revealed a higher in hospital mortality rate. In the longterm, the arterial switch provides patients significant transplant-free survival advantage when compared to the atrial switch (56).

\section{Fontan Palliation for Single Ventricle Patients}

Complex single ventricle anatomy is rare with a prevalence of approximately 1 in 10,000 live births $(57,58)$. It has been 50 years since Francis Fontan pioneered the operation that today bears his name. The Fontan procedure was first described in 1971 though first performed in 1968 for tricuspid atresia. Surgery is the main treatment for these patients with the tricuspid atresia anatomy. Without operation, the survival rate to one year is $33 \%$ and ten years is $10 \%$. The malformation of tricuspid atresia consists of complete agenesis of the tricuspid valve with an absence of a direct communication between the right atrium and RV. Fontan also incorporated a valved homograft between the IVC and the right atrium and a second valved homograft between the right atrium and the left pulmonary artery (59). The final operation consisted of the classic Glenn SVC-to-right pulmonary artery shunt as well as the right atrium-to-left pulmonary artery connection with the two homografts, as outlined before. He published his results from the first three patients in 1971 (59). Kreutzer et al. in 1973 presented a surgical modification. They described a connection between the right atrial appendage and the main pulmonary artery by means of a pulmonary homograft or the patient's own pulmonary annulus, but without a valved homograft at the IVC-right atrial junction. In this situation, the continuity of the pulmonary arteries is conserved $(60,61)$.

The Fontan operation is now offered for a vast array of congenital cardiac lesions when a circulation with two ventricles cannot be achieved. The procedure is usually performed in patients with a hypoplastic right or left ventricle with associated defects in the atrioventricular valves, and possibly other features where the anatomy eliminates the possibility of biventricular repair. Patients that require this procedure commit to univentricular circulation, but without the surgical intervention, there would be more childhood deaths and less patients surviving into adulthood $(57,58)$. The palliative operation has significantly improved the survival rate of these infants who are typically born with only one functioning ventricle. With advancements in technology and improvement in medical management, patient's now have a 30 -year survival of $>80 \%$ in the current era. The estimated number of patients worldwide with the Fontan circulation who are alive today is around 70,000 with the expectation of this sub group doubling in the next two decades (62). In general, the operation has demonstrated its success with a growing population of patients having this unique Fontan circuit physiology. However, with long-term follow up, the circulation of these patients have recently shown to have multisystem effects with both expected and unexpected sequelae (62-64).

In the absence of a sub-pulmonary ventricle, Fontan circulation is described by chronically elevated systemic venous pressures and decreased cardiac output. The 
addition of this acquired abnormal circulation to innate abnormalities associated with single-ventricle CHD exposes these patients to a variety of complications. Circulatory failure, systemic ventricular dysfunction, systemic atrioventricular valve regurgitation, arrhythmia, plastic bronchitis and protein-losing enteropathy are potential long-term complications of the Fontan circulation (65). Abnormalities in body composition, bone structure, and growth have all been described. Liver fibrosis and renal dysfunction are common and may progress over time $(62,66)$. Cognitive, neuropsychological, and behavioral deficits are highly prevalent. The proportion of adults with the Fontan circulation is increasing and there is a clear need for consensus on how to best follow up with these patients and treat their complications (62).

The failing Fontan has become an evolving challenge with several of its associated complications and the lack of effective management strategies which has led to an increasing number of patients being considered for a heart or heart liver transplantation. In addition, having multiple previous operations increases the likelihood of the sensitization of the recipient to the donor organ often reducing the donor pool (67). Prolonged donor ischemic times are more likely, given the need for complex explanation of the recipient's heart. The outcomes of Fontan transplants are not comparable to non-Fontan ACHD transplants. Despite higher early mortality, longterm survival is superior in the ACHD population when compared to the non-ACHD population $(68,69)$.

\section{Mechanical Circulatory Support and Cardiac Transplantation}

The complexity of survivors with CHD has significantly increased over the last two decades. This has led to a growing number of adults with late-onset complications, including an increase in hospital admissions for ACHD patients with heart failure (HF) (12). Though mechanical circulatory support options are arising, the surgical procedure of choice for eligible patients with advanced HF is cardiac transplantation. Although there is an increasing need, the number of patients receiving transplants over the past decade has not changed (70). The number of ACHD heart transplant recipients continues to grow rapidly with a $40 \%$ increase over the last two decades (71). Findings show that out of the adult heart transplants, only $3.3 \%$ of them are patients with ACHD (72).

Heart failure in ACHD is vastly different to that in acquired heart disease. Unlike acquired HF in which pharmacological goal directed medical therapies are the cornerstone for protecting and improving ventricular function, ACHD-related CHF relies heavily upon structural interventions, either surgical or percutaneously done via cardiac catheterization. Morphologic systemic $\mathrm{RV}$, altered coronary perfusion, and ventricular noncompaction are all mechanisms that can lead to the development of late ventricular dysfunction. Some of the indications for cardiac transplantation in ACHD patients include systemic ventricular failure with refractory medical therapy, patients with failing Fontan physiology and progressive cyanosis leading to functional decline (73). Transplantation in ACHD patients may be complex and may require extensive reconstruction of the branch pulmonary arteries, systemic veins, or the aorta. Significant vasoplegia, prolonged bleeding, and graft dysfunction can complicate the immediate post-transplant period. The post transplant mortality rate ranges between $14 \%$ to $39 \%$ for post-transplant operations, with the majority of early morality occurring in ACHD patients with univentricular CHD.

There has been a significant increase in MCS use as a bridge to transplantation $(17 \%)$ in patients with acquired HF, but there has been little change in MCS use in ACHD patients with only $3 \%$ receiving a VAD at the time of cardiac transplantation. Higher mortality rates have been seen in patients receiving MCS, regardless of the type received (72,74-76). MCS is associated with significant morbidity and uncertain long-term outcomes in ACHD patients. Careful evaluation and selection is important to determine if the patient may be a candidate for alternative therapies. A variety of ventricular assist devices (VADs) have been used to assist the failing systemic RV in patients with L-TGA or d-TGA after atrial switch operations. Although there is sparse outcomes data, ACHD patients are also less likely to receive a VAD as a bridge to transplantation. Listed ACHD patients are more likely to experience cardiovascular death either due to HF or sudden death than adults with acquired $\operatorname{HF}(74,77,78)$.

There have been two important considerations raised regarding patients with CHD in the most up-to-date guidelines for MCS. The first is the requisite for assessment of complete cardiac morphology before implantation of MCS including the location of great vessels, shunts, and any collateral vessels. The second is the assessment for total heart replacement strategies in patients who are not candidates for mechanical circulatory support (79). 
There remain many surgical challenges in transplantation for ACHD patients. Several ACHD patients have had prior open heart surgical procedures with multiple prior sternotomies, which can increase the risk of adhesions and bleeding, lengthen the operative procedure, and increase the need for reoperation $(77,80)$. A reconstruction is commonly required, especially in Fontan patients (85.4\% for Fontan patients versus $42.9 \%$ for other CHD diagnoses), which is associated with increased mortality risk (80). Patients with prior atrial switch procedures (i.e., Mustard/Senning) often have calcified baffles and previous stents that need to be removed, which leaves less tissue for atrial anastomoses. Bicaval and pulmonary venous anastomoses are preferable in these situations (81). Overall, there has been improvement in long term survival in more contemporary studies (82). High-risk patient subsets have been defined, and significant improvement has been made in evidence-based guidelines on indications for mechanical circulatory support, cardiac transplant and the intraoperative management of complex cardiac reconstructions. With appropriate patient selection, more aggressive use of MCS, and earlier referral of patients for transplant, both short and long term outcomes should continue to improve.

\section{Conclusions}

Advances in early management of CHD and improvements in congenital cardiac surgery have led to a significant growth in adults with CHD. This brief review examines the epidemiology, surgical procedures and outcomes for some of the more common complex CHD lesions in adults. Contemporary cardiac surgery for ACHD continues to improve with low surgical mortality, improved functional status and excellent long-term outcome.

\section{Acknowledgments}

Funding: None.

\section{Footnote}

Provenance and Peer Review: This article was commissioned by the Guest Editor (Raghav A. Murthy) for the series "Management of Congenital Heart Disease" published in Fournal of Thoracic Disease. The article was sent for external peer review organized by the Guest Editor and the editorial office.
Conflicts of Interest: The series "Management of Congenital Heart Disease" was commissioned by the editorial office without any funding or sponsorship. The authors have no other conflicts of interest to declare.

Ethical Statement: The authors are accountable for all aspects of the work in ensuring that questions related to the accuracy or integrity of any part of the work are appropriately investigated and resolved.

Open Access Statement: This is an Open Access article distributed in accordance with the Creative Commons Attribution-NonCommercial-NoDerivs 4.0 International License (CC BY-NC-ND 4.0), which permits the noncommercial replication and distribution of the article with the strict proviso that no changes or edits are made and the original work is properly cited (including links to both the formal publication through the relevant DOI and the license). See: https://creativecommons.org/licenses/by-nc-nd/4.0/.

\section{References}

1. Marelli AJ, Ionescu-Ittu R, Mackie AS, et al. Lifetime prevalence of congenital heart disease in the general population from 2000 to 2010. Circulation 2014;130:749-56.

2. Ottaviani G, Buja LM. Update on congenital heart disease and sudden infant/perinatal death: from history to future trends. J Clin Pathol 2017;70:555-62.

3. Gilboa SM, Devine OJ, Kucik JE, et al. Congenital Heart Defects in the United States: Estimating the Magnitude of the Affected Population in 2010. Circulation 2016;134:101-9.

4. van der Linde D, Konings EE, Slager MA, et al. Birth prevalence of congenital heart disease worldwide: a systematic review and meta-analysis. J Am Coll Cardiol 2011;58:2241-7.

5. Marelli AJ, Mackie AS, Ionescu-Ittu R, et al. Congenital heart disease in the general population: changing prevalence and age distribution. Circulation 2007;115:163-72.

6. Khairy P, Ionescu-Ittu R, Mackie AS, et al. Changing mortality in congenital heart disease. J Am Coll Cardiol 2010;56:1149-57.

7. Bansal N, Balakrishnan PL, Aggarwal S. Prostaglandin Infusion in Neonate With Severe Coarctation of the Aorta With Closed Ductus Arteriosus-A Case Report and Review of the Literature. World J Pediatr Congenit Heart 
Surg 2019:2150135118799635. [Epub ahead of print].

8. Nance JW, Ringel RE, Fishman EK. Coarctation of the aorta in adolescents and adults: A review of clinical features and CT imaging. J Cardiovasc Comput Tomogr 2016;10:1-12.

9. Rao PS. Should balloon angioplasty be used instead of surgery for native aortic coarctation? Br Heart J 1995;74:578-9.

10. Rao PS, Koscik R. Validation of risk factors in predicting recoarctation after initially successful balloon angioplasty for native aortic coarctation. Am Heart J 1995;130:116-21.

11. Campbell M. Natural history of coarctation of the aorta. Br Heart J 1970;32:633-40.

12. Stout KK, Daniels CJ, Aboulhosn JA, et al. 2018 AHA/ ACC Guideline for the Management of Adults With Congenital Heart Disease: Executive Summary: A Report of the American College of Cardiology/American Heart Association Task Force on Clinical Practice Guidelines. J Am Coll Cardiol 2019;73:1494-563.

13. Feltes TF, Bacha E, Beekman RH, 3rd, et al. Indications for cardiac catheterization and intervention in pediatric cardiac disease: a scientific statement from the American Heart Association. Circulation 2011;123:2607-52.

14. Silversides CK, Kiess M, Beauchesne L, et al. Canadian Cardiovascular Society 2009 Consensus Conference on the management of adults with congenital heart disease: outflow tract obstruction, coarctation of the aorta, tetralogy of Fallot, Ebstein anomaly and Marfan's syndrome. Can J Cardiol 2010;26:e80-97.

15. Baumgartner H, Bonhoeffer P, De Groot NM, et al. ESC Guidelines for the management of grown-up congenital heart disease (new version 2010). Eur Heart J 2010;31:2915-57.

16. Lacour-Gayet F, Bruniaux J, Serraf A, et al. Hypoplastic transverse arch and coarctation in neonates. Surgical reconstruction of the aortic arch: a study of sixty-six patients. J Thorac Cardiovasc Surg 1990;100:808-16.

17. Pinzon JL, Burrows PE, Benson LN, et al. Repair of coarctation of the aorta in children: postoperative morphology. Radiology 1991;180:199-203.

18. Liberthson RR, Pennington DG, Jacobs ML, et al. Coarctation of the aorta: review of 234 patients and clarification of management problems. Am J Cardiol 1979;43:835-40.

19. Crawford FA, Jr., Sade RM. Spinal cord injury associated with hyperthermia during aortic coarctation repair. J Thorac Cardiovasc Surg 1984;87:616-8.

20. Brewer LA, 3rd, Fosburg RG, Mulder GA, et al. Spinal cord complications following surgery for coarctation of the aorta. A study of 66 cases. J Thorac Cardiovasc Surg 1972;64:368-81.

21. Tabry I, Rush M. Therapeutic Alternatives in the Management of Late Complications of Surgery for Isolated Coarctation of the Aorta. Aorta (Stamford) 2018;6:59-64.

22. Piciucchi S, Goodman LR, Earing M, et al. Aortic aneurysms: delayed complications of coarctation of the aorta repair using Dacron patch aortoplasty. J Thorac Imaging 2008;23:278-83.

23. Galea J, Ellul S, Schembri A, et al. Ebstein anomaly: a review. Neonatal Netw 2014;33:268-74.

24. Krieger EV, Valente AM. Diagnosis and management of ebstein anomaly of the tricuspid valve. Curr Treat Options Cardiovasc Med 2012;14:594-607.

25. Dearani JA, Mora BN, Nelson TJ, et al. Ebstein anomaly review: what's now, what's next? Expert Rev Cardiovasc Ther 2015;13:1101-9.

26. Brown ML, Dearani JA. Ebstein malformation of the tricuspid valve: current concepts in management and outcomes. Curr Treat Options Cardiovasc Med 2009;11:396-402.

27. Shiina Y, Matsuyama TA, Adachi I, et al. Surgery in a contemporary adult cohort of patients with Ebstein malformation of tricuspid valve and relation with ECG markers, atrial fibrosis and arrhythmic load. Int J Cardiol 2013;168:1551-2.

28. Holst KA, Dearani JA, Said SM, et al. Surgical Management and Outcomes of Ebstein Anomaly in Neonates and Infants: A Society of Thoracic Surgeons Congenital Heart Surgery Database Analysis. Ann Thorac Surg 2018;106:785-91.

29. Holst KA, Dearani JA, Said S, et al. Improving Results of Surgery for Ebstein Anomaly: Where Are We After 235 Cone Repairs? Ann Thorac Surg 2018;105:160-8.

30. Carpentier A, Chauvaud S, Mace L, et al. A new reconstructive operation for Ebstein's anomaly of the tricuspid valve. J Thorac Cardiovasc Surg 1988;96:92-101.

31. Lange R, Burri M, Eschenbach LK, et al. Da Silva's cone repair for Ebstein's anomaly: effect on right ventricular size and function. Eur J Cardiothorac Surg 2015;48:31620; discussion 320-1.

32. Attenhofer Jost CH, Connolly HM, Scott CG, et al. Outcome of cardiac surgery in patients 50 years of age or older with Ebstein anomaly: survival and functional improvement. J Am Coll Cardiol 2012;59:2101-6.

33. Chauvaud S. Surgery of Ebstein anomaly. J Thorac 
Cardiovasc Surg 2007;134:1381; author reply 1381.

34. Forman J, Beech R, Slugantz L, et al. A Review of Tetralogy of Fallot and Postoperative Management. Crit Care Nurs Clin North Am 2019;31:315-28.

35. Pillutla P, Shetty KD, Foster E. Mortality associated with adult congenital heart disease: Trends in the US population from 1979 to 2005 . Am Heart J 2009;158:874-9.

36. Saygi M, Ergul Y, Tola HT, et al. Factors affecting perioperative mortality in tetralogy of Fallot. Pediatr Int 2015;57:832-9.

37. Dennis M, Moore B, Kotchetkova I, et al. Adults with repaired tetralogy: low mortality but high morbidity up to middle age. Open Heart 2017;4:e000564.

38. Smith CA, McCracken C, Thomas AS, et al. Longterm Outcomes of Tetralogy of Fallot: A Study From the Pediatric Cardiac Care Consortium. JAMA Cardiol 2019;4:34-41.

39. Fraser CD, Bacha EA, Comas J, et al. Tetralogy of Fallot. Semin Thorac Cardiovasc Surg 2015;27:189-204.

40. Cuypers JA, Menting ME, Konings EE, et al. Unnatural history of tetralogy of Fallot: prospective followup of 40 years after surgical correction. Circulation 2014;130:1944-53.

41. Hussein N, Honjo O, Haller C, et al. Hands-On Surgical Simulation in Congenital Heart Surgery: Literature Review and Future Perspective. Semin Thorac Cardiovasc Surg 2019. [Epub ahead of print].

42. Bacha EA. Introduction to "recent advances in congenital heart surgery" for surgical review "pediatric cardiology". Pediatr Cardiol 2007;28:77-8.

43. Mosca RS. Pulmonary valve replacement after repair of tetralogy of Fallot: Evolving strategies. J Thorac Cardiovasc Surg 2016;151:623-5.

44. McRae ME, Coleman B, Atz TW, et al. Patient outcomes after transcatheter and surgical pulmonary valve replacement for pulmonary regurgitation in patients with repaired tetralogy of Fallot: A quasi-meta-analysis. Eur J Cardiovasc Nurs 2017;16:539-53.

45. Weinberg CR, McElhinney DB. Pulmonary valve replacement in tetralogy of Fallot. Circulation 2014;130:795-8.

46. Bokma JP, Geva T, Sleeper LA, et al. A propensity scoreadjusted analysis of clinical outcomes after pulmonary valve replacement in tetralogy of Fallot. Heart 2018;104:738-44.

47. Alkashkari W, Alsubei A, Hijazi ZM. Transcatheter Pulmonary Valve Replacement: Current State of Art. Curr Cardiol Rep 2018;20:27.
48. d'Udekem Y, Galati JC, Konstantinov IE, et al. Intersurgeon variability in long-term outcomes after transatrial repair of tetralogy of Fallot: 25 years' experience with 675 patients. J Thorac Cardiovasc Surg 2014;147:880-6.

49. Balderman SC, Athanasuleas CL, Anagnostopoulos CE. The atrial baffle operation for transposition of the great arteries. A review of 591 reported cases. Ann Thorac Surg 1974;17:114-21.

50. Zavanella C, Subramanian S. Review: surgery for transposition of the great arteries in the first year of life. Ann Surg 1978;187:143-50.

51. Breckenridge IM, Stark J, Bonham-Carter RE, et al. Mustard's operation for transposition of the great arteries. Review of 200 cases. Lancet 1972;1:1140-2.

52. Rastelli GC, Wallace RB, Ongley PA. Complete repair of transposition of the great arteries with pulmonary stenosis. A review and report of a case corrected by using a new surgical technique. Circulation 1969;39:83-95.

53. Marathe SP, Talwar S. Surgery for transposition of great arteries: A historical perspective. Ann Pediatr Cardiol 2015;8:122-8.

54. Malankar DP, Patil S, Mali S, et al. Use of Left Ventricular Assist Device After Arterial Switch Operation in Late Presenting D-Transposition of Great Arteries-A Technique for Retraining the Regressed Left Ventricle. World J Pediatr Congenit Heart Surg 2019;10:223-7.

55. Watanabe N, Mainwaring RD, Carrillo SA, et al. Left Ventricular Retraining and Late Arterial Switch for D-Transposition of the Great Arteries. Ann Thorac Surg 2015;99:1655-61; discussion 1661-3.

56. Khairy P, Clair M, Fernandes SM, et al. Cardiovascular outcomes after the arterial switch operation for D-transposition of the great arteries. Circulation 2013;127:331-9.

57. Qu Y, Liu X, Zhuang J, et al. Incidence of Congenital Heart Disease: The 9-Year Experience of the Guangdong Registry of Congenital Heart Disease, China. PLoS One 2016;11:e0159257.

58. Moodie DS, Ritter DG, Tajik AH, et al. Long-term follow-up after palliative operation for univentricular heart. Am J Cardiol 1984;53:1648-51.

59. Fontan F, Baudet E. Surgical repair of tricuspid atresia. Thorax 1971;26:240-8.

60. Kreutzer G, Galindez E, Bono H, et al. An operation for the correction of tricuspid atresia. J Thorac Cardiovasc Surg 1973;66:613-21.

61. Kreutzer GO, Schlichter AJ, Kreutzer C. The Fontan/ 
Kreutzer procedure at 40: an operation for the correction of tricuspid atresia. Semin Thorac Cardiovasc Surg Pediatr Card Surg Annu 2010;13:84-90.

62. Rychik J, Atz AM, Celermajer DS, et al. Evaluation and Management of the Child and Adult With Fontan Circulation: A Scientific Statement From the American Heart Association. Circulation 2019:CIR0000000000000696. [Epub ahead of print].

63. Schwartz I, McCracken CE, Petit CJ, et al. Late outcomes after the Fontan procedure in patients with single ventricle: a meta-analysis. Heart 2018;104:1508-14.

64. Marathe SP, Zannino D, Shi WY, et al. Two Ventricles Are Not Better Than One in the Fontan Circulation: Equivalent Late Outcomes. Ann Thorac Surg 2019;107:852-9.

65. Kay WA, Moe T, Suter B, et al. Long Term Consequences of the Fontan Procedure and How to Manage Them. Prog Cardiovasc Dis 2018;61:365-76.

66. Ofei SY, Gariepy C, Hanje J, et al. Liver fibrosis in adults with Fontan palliation: Do common screening studies predict disease severity? Int J Cardiol 2015;181:174-5.

67. Hosseinpour AR, Cullen S, Tsang VT. Transplantation for adults with congenital heart disease. Eur J Cardiothorac Surg 2006;30:508-14.

68. Murtuza B, Hermuzi A, Crossland DS, et al. Impact of mode of failure and end-organ dysfunction on the survival of adult Fontan patients undergoing cardiac transplantation. Eur J Cardiothorac Surg 2017;51:135-41.

69. Rossano JW, Shaddy RE. Heart transplant after the Fontan operation. Cardiol Young 2013;23:841-6.

70. Opotowsky AR, Siddiqi OK, Webb GD. Trends in hospitalizations for adults with congenital heart disease in the U.S. J Am Coll Cardiol 2009;54:460-7.

71. Ross HJ, Law Y, Book WM, et al. Transplantation and Mechanical Circulatory Support in Congenital Heart Disease: A Scientific Statement From the American Heart Association. Circulation 2016;133:802-20.

72. Serfas JD, Patel PA, Krasuski RA. Heart Transplantation and Mechanical Circulatory Support in Adults with

Cite this article as: Chan A, Aijaz A, Zaidi AN. Surgical outcomes in complex adult congenital heart disease: a brief review. J Thorac Dis 2020;12(3):1224-1234. doi: 10.21037/ jtd.2019.12.136
Congenital Heart Disease. Curr Cardiol Rep 2018;20:81.

73. Riggs KW, Zafar F, Radzi Y, et al. Adult Congenital Heart Disease: Current Early Expectations after Cardiac Transplantation. Ann Thorac Surg 2020;109:480-6.

74. Gelow JM, Song HK, Weiss JB, et al. Organ allocation in adults with congenital heart disease listed for heart transplant: impact of ventricular assist devices. J Heart Lung Transplant 2013;32:1059-64.

75. Cedars A, Tecson KM, Zaidi AN, et al. Impact of Durable Ventricular Assist Device Support on Outcomes of Patients with Congenital Heart Disease Waiting for Heart Transplant. ASAIO J 2019. [Epub ahead of print].

76. Maxwell BG, Wong JK, Sheikh AY, et al. Heart transplantation with or without prior mechanical circulatory support in adults with congenital heart disease. Eur J Cardiothorac Surg 2014;45:842-6.

77. Davies RR, Russo MJ, Yang J, et al. Listing and transplanting adults with congenital heart disease. Circulation 2011;123:759-67.

78. Everitt MD, Donaldson AE, Stehlik J, et al. Would access to device therapies improve transplant outcomes for adults with congenital heart disease? Analysis of the United Network for Organ Sharing (UNOS). J Heart Lung Transplant 2011;30:395-401.

79. Feldman D, Pamboukian SV, Teuteberg JJ, et al. The 2013 International Society for Heart and Lung Transplantation Guidelines for mechanical circulatory support: executive summary. J Heart Lung Transplant 2013;32:157-87.

80. Davies RR, Sorabella RA, Yang J, et al. Outcomes after transplantation for "failed" Fontan: a single-institution experience. J Thorac Cardiovasc Surg 2012;143:118392.e4.

81. Chen JM, Davies RR, Mital SR, et al. Trends and outcomes in transplantation for complex congenital heart disease: 1984 to 2004. Ann Thorac Surg 2004;78:1352-61; discussion 1352-61.

82. Bryant R 3rd. Overview of adult congenital heart transplants, Morales D. Overview of adult congenital heart transplants. Ann Cardiothorac Surg 2018;7:143-51. 